\title{
CONSERVAÇÃO DE SUPERFÍCIES PÉTREAS EM MONUMENTOS.
}

\section{ASPECTOS METODOLÓGICOS}

\author{
J. Delgado Rodrigues \\ Geólogo, Investigador-Coordenador do LNEC (Ap.), Lisboa, Portugal \\ delgado@Inec.pt
}

Resumo: A conservação de monumentos é uma área de interesses profissionais múltiplos, lida com problemas de índoles muito diversas, exige abordagens muito versáteis e adaptativas para resolver problemas que frequentemente não encaixam em conceitos normalizados, e funciona com incertezas mal aceites pela legislação e práticas correntes em actividades da indústria da construção com as quais frequentemente conflitua. A necessidade de competências específicas para actuar sobre o património cultural é hoje reconhecida sem grande contestação, mas nem os conteúdos dessas competências, nem as formas de os obter são assunto resolvido. A clarificação dos domínios de intervenção e a delimitação dos específicos campos de actuação são aspectos relevantes para minimizar conflitos, mas as formas de as definir nem sempre foram objectivas e a sua implementação é muitas vezes pouco clara. A qualificação dos agentes, o recurso a equipas multidisciplinares e a promoção do trabalho interdisciplinar promovem a elevação da qualidade dos projectos e das intervenções. $O$ estabelecimento de regras claras entre tutelas, consultores e executantes facilita o diálogo e promove o estabelecimento de relações mais justas e uma maior probabilidade de serem atingidos os melhores resultados. $\mathrm{O}$ artigo propõe-se discutir alguns destes aspectos, principalmente do ponto de vista dos cientistas da conservação, focando-se no seu papel como intervenientes activos em equipas multidisciplinares responsáveis pela tomada de decisão e de supervisão das intervenções de conservação.

Palavras Chave: conservação de monumentos; conservation scientist; multidisciplinaridade; qualificação das intervenções

Abstract: CONSERVATION OF STONE SURFACE IN MONUMENTS. METHODOLOGICAL ASPECTS. The conservation of monuments is an area of multiple professional interests, deals with problems of very diverse nature, requires very versatile and adaptive approaches to solve problems that often do not fit into standard concepts, and deals with uncertainties not well accepted by law and by the current practices of the construction industry with which it often conflicts. The need for specific skills to act on the cultural heritage is now recognized without much controversy, but neither the contents of these skills nor the ways of obtaining them are consensual matters. Clarification of fields of intervention and the delimitation of the respective competence domains are relevant to minimize conflicts, but the way they have been defined were not always objective and its implementation is often unclear. The qualification of agents, the preference for multidisciplinary teams and the encouragement of interdisciplinary work will help rising the quality of projects and interventions. The establishment of clear interrelation rules among curators, consultants and contractors facilitates dialogue and creates an ambiance of fairer relationships with higher chances to reach the best expectable results. The article aims to discuss some of these aspects, especially from the point of view of conservation scientists, focusing on their role as active players in multidisciplinary teams responsible for decision-making and supervision of conservation interventions.

Keywords: conservation of monuments, conservation scientist, multidisciplinarity, quality of interventions

\section{INTRODUÇÃO}

A conservação de monumentos é uma área profissional na fronteira entre as ciências exactas e naturais e as ciências sociais e lida com problemas que incluem a materialidade dos objectos e das construções e a subjectividade e imaterialidade próprias dos juízos, opções e decisões que a sociedade exerce sobre eles. Deve ser, em consequência, uma convergência de valências científicas e um espaço de diálogo entre Ciência e Sociedade.

Por sua vez, a diversidade de tipologias do património, em geral, e dos monumentos pétreos, em particular, implica lidar com problemas de índoles muito diversas, o que exige abordagens muito versáteis e adaptativas para resolver problemas que frequentemente não encaixam em conceitos normalizados. As abordagens preparatórias para intervenções de conservação, mesmo se apenas delimitadas aos aspectos técnicos e científicos, precisam, pois, de contribuições complementares, que requerem equipas multidisciplinares.
É geralmente aceite que os aspectos científicos técnicos são úteis para preparar as intervenções de conservação, ainda que nem sempre se aplique a noção (de aceitação pacífica) de que se pode investigar por disciplinas científicas, mas que a aplicação exige abordagem multidisciplinar e que as melhores interpretações se preparam em contexto interdisciplinar.

Os conceitos que suportam a classificação, protecção e salvaguarda, bem como as noções teóricas que justificam as acções e as medidas a aplicar, sendo do domínio das humanidades, não têm soluções únicas, pelo que se opera aqui num domínio caracterizado pela diversidade, pela especulação teórica, pela subjectividade e pela controvérsia. Não podendo esta lógica ser transformada na sua raiz, é no diálogo e na multiplicidade de participações que se pode ir buscar a fórmula para operar em tais circunstâncias, sem se ficar bloqueado na análise ou paralisado na decisão.

Por natureza, esta actividade lida com objectos únicos, muitos construídos segundo práticas tradicionais hoje maioritariamente desaparecidas ou preteridas, que sofreram transformações, adaptações, adições ou perdas que os tornaram 
objectos singulares, complexos, e frequentemente mal conhecidos. Intervir nestes objectos não pode ser, por isso, uma prática operada segundo modelos próprios de obra nova, pelo que conceitos como projecto, normalização, especificações, caderno de encargos, requisitos processuais, formação de agentes, entre outros, exigem definições específicas e adaptadas à natureza muito particular deste tipo de obras, não podendo, de forma alguma, ser transcritos acriticamente da prática das actividades da indústria da construção.

Ao serem duas áreas da economia que disputam um mesmo negócio, a actividade de conservação e restauro e a indústria da construção são actividades conflituantes, pelo que a intervenção sobre monumentos não pode ser deixada à livre disputa de interesses, pois nesta disputa nunca é o monumento, nem muito menos a Sociedade, que ficam a ganhar.

As relações entre intervenientes, entre prescritores e actores, e entre ambos e as autoridades constituem um domínio em geral mal definido, mal regulado e frequentemente deliberadamente remetido para um limbo onde os interesses legítimos podem ter grande dificuldade em manobrar.

Este artigo aborda alguns aspectos que servem para ilustrar estas opiniões e ao mesmo tempo para apontar algumas linhas de acção que o autor suporta na sua prática de participação em intervenções de conservação de índoles diversas.

\section{OS ASPECTOS DE NATUREZA CIENTÍFICA. O MATERIAL E O IMATERIAL}

Uma intervenção de conservação num qualquer monumento deve ser o culminar de um processo, que passará pelo (re)conhecimento do objecto, pela identificação dos problemas que apresenta e dos impactes que provocam, pela interpretação das causas desses problemas, pela definição de soluções para lhes contrapor e pela elaboração de especificações para as implementar, pela selecção criteriosa dos actores e pela definição de regras de relacionamento justas e eficazes, e pela supervisão próxima e especializada dessa intervenção.

O reconhecimento de que uma intervenção deve ser um processo e não uma empreitada é um passo decisivo para minimizar os riscos de omitir elementos relevantes e de cometer erros básicos de análise e de valoração dos bens em causa. Tomando o modelo das oito fases (DELGADO RODRIGUES \& GROSSI, 2004) ou outro qualquer faseamento, verse-á que há temas e objectivos diferenciados, que há necessidade de convocar diferentes especializações e que uma qualquer acção a ser definida pressupõe um conjunto mais ou menos vasto de conhecimentos prévios que a justificam e enformam.

Se o reconhecimento e estudo da materialidade é um ponto inquestionável da preparação para a intervenção (afinal apenas se restaura a matéria da obra de arte, como diz Brandi (BRANDI, 2006), não podemos esquecer que os bens culturais são um produto da Sociedade e que é ela que lhe atribui os valores e define os limites do seu uso e as linhas para a sua preservação. Como refere U. Meneses (2009), "atuar no campo do património cultural é se defrontar, antes de mais nada, com a problemática do valor, que ecoa em qualquer esfera do campo", e é, por isso, de questões imateriais que teremos também de tratar, portanto.

Conjugar as informações sobre a materialidade com as implicações e constrangimentos da imaterialidade constitui o cerne das profissões ligadas à conservação de bens culturais e isso pressupõe uma formação dedicada dos diferentes intervenientes, começando pelas profissões que exigem maiores qualificações científicas. Sejam eles provenientes das ciências exactas e naturais, sejam das humanidades ou doutras. Pressupõe, também, que a complexidade não é abarcável por uma qualquer delas, e só a colaboração pluridisciplinar permitirá atingir a compreensão satisfatória dos problemas e das suas implicações.

Nas vertentes científicas, definiu-se o termo de "conservation scientist" ${ }^{1}$ para identificar o profissional de um ramo das ciências naturais que tenha formação aprofundada em qualquer das ciências relevantes (física, química, geologia, biologia, engenharia, etc.) e seja capaz de aplicar esses conhecimentos em ambiente de diálogo entre a materialidade e a imaterialidade do bem cultural em causa. Isto é, fazer análises ao MEV ou em qualquer outro equipamento mais ou menos sofisticado de umas tantas amostras de um monumento, por muito úteis que sejam os resultados, não faz do analista necessariamente um "conservation scientist".

A preparação das acções que compõem uma intervenção de conservação exige a recolha de informação científica de diferentes naturezas e proveniências, mas exige também o conhecimento aprofundado do tipo de soluções disponíveis, dos produtos existentes no mercado e, sobretudo, dos procedimentos necessários e exigíveis para a sua implementação. Requer-se, aqui, a capacidade de

\footnotetext{
${ }^{1}$ Esta designação foi proposta pelo ICCROM pela Declaração de Bologna emitida no encontro de Bolonha de 1999 (University Postgraduate Curricula for Conservation Scientists, Proceedings of the International Seminar, Bologna, Italy, 26-27 November 1999, ICCROM, Rome, 2000). A tradução directa para português seria "cientistas da conservação" que, no nosso entender, coloca demasiada ênfase no termo "cientista", quase sempre entendido como aplicável aos profissionais não ligados às questões práticas. A alternativa de "profissionais das ciências da conservaç̃o" traduz melhor o praticas. A alternativa de "profissionais das ciencias da consenvaça traduz mesto 0 opção pessoal, dentro deste contexto de análise.
} 
interpretar informação diversa e de a transformar em especificação exequível. Isto é, pressupõe-se uma capacidade de análise interdisciplinar e uma capacidade de decisão orientada para a resolução dos problemas reais de forma eficaz e eficiente.

Para corresponder a esta tipificação profissional, o interessado deverá ser um cientista em constante aprendizagem e em permanente adaptação a novas realidades e exigências.

\section{A PREPARAÇÃO DAS INTERVENÇÕES. AS REGRAS E O DIÁLOGO}

Uma intervenção de conservação deve girar em torno do que se poderia chamar o triângulo de ouro: problemas-soluções-acções (Figura 1). Decide-se por uma intervenção porque há problemas, estes precisam de soluções e estas terão de ser concretizadas com acções. Cada vértice do triângulo tem os seus actores típicos e cada actor tem as suas funções e responsabilidade. Cada lado representa necessidades específicas de interacção e de diálogo. No centro estará, sempre, a preservação do bem cultural.

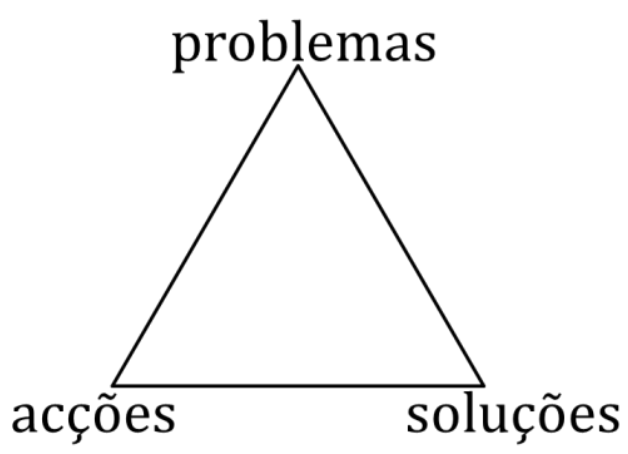

Figura 1. Triângulo de ouro das intervenções de conservação.

Pelo lado dos "problemas" devemos incluir a identificação e caracterização dos danos aparentes, mas também todos os aspectos do contexto do objecto que possam ajudar a melhor entender esses problemas e as suas causas. Entender um determinado processo construtivo, identificar intervenções de conservação passadas ou esclarecer o faseamento da construção e das transformações subsequentes são componentes relevantes dos estudos preparatórios. Nesta explanação simples, podemos desde logo perceber a diversidade de actores que aqui têm cabimento; os contextos e as informações de base necessitam de áreas como a História da Arte, a Arquitectura, e outras, enquanto que, na parte material do "problema" e de acordo com as suas tipologia e severidade, podem entrar especialidades como a Engenharia, a Geologia, a Química, a Biologia, etc.

No vértice das "soluções" aparece a imperiosa necessidade de entender que elas se destinam a resolver um problema, que não devem ser propostas soluções para "não-problemas" e que não devem ficar problemas sem soluções. Ainda que tal pareça digno do Sr. de La Palisse, infelizmente muitos casos existem em que tal preceito não se cumpre, e nem sempre pela simples razão de esquecimento ou impreparação. São questões do domínio da Ética e da Responsabilidade Social dos intervenientes, também eles essenciais para atingir os objectivos de forma meritória e socialmente aceitável.

Num processo de identificação de soluções e de preparação de acções para uma intervenção, poderíamos elencar uma sequência racional de passos orientadores: i) cada acção deve ter um problema como destino; ii) deve ser potencialmente eficaz, isto é, deve ser capaz de resolver ou de contribuir para a resolução do problema; iii) deve ser exequível, nas condições de operacionalidade em causa e pelos agentes disponíveis; iv) deve conduzir a situação compatível com o existente; v) a situação obtida pela acção deve manter-se por um período razoável de tempo (função do tipo de acção, esse período pode ser curto, como na limpeza ou no tratamento com um biocida, de médio prazo, como na hidrofugação, ou ilimitado, como na consolidação).

Percebe-se que os passos iv) e v) são os mais complexos e difíceis de delimitar. Em termos mais correntes, diz-se que uma acção não deve introduzir modificações para além de limites aceitáveis (definir estes limites é em si mesmo uma das dificuldades do processo) e não deve induzir comportamentos nocivos a curto, médio e longo prazo. A discussão em torno destes conceitos já vem de muito longe e pode ser traduzida por questões práticas, como sejam, que método de limpeza devo usar, que grau de limpeza devo atingir, que consolidante devo aplicar, que aumento de resistência mínimo e máximo devo aceitar na consolidação, que profundidade deve atingir o consolidante, etc. Estes têm sido temas abundantemente abordados nas ciências da conservação (GAURI, et al. 1976, SASSE \& SNETHLAGE 1997, LAURENZI TABASSO \& SIMON 2006, DELGADO RODRIGUES \& GROSSI 2007, REVEZ \& DELGADO RODRIGUES 2016) e devem ainda continuar por mais algum tempo até que as acções e os seus limites estejam razoavelmente bem definidos e aceites pelas comunidade científica e técnica e às profissões ligadas à conservação de monumentos.

As dificuldades de delimitação das acções e os riscos que intrinsecamente trazem a elas associados impõem atitudes de prudência, pois se é suposto que as acções resolvam os problemas, não se espera que eles fiquem sem resolução, mas sobretudo não se admite que delas resultem novos problemas, porventura de resolução ainda mais difícil do que os anteriores. Na ética da conservação, é recomendado 
o princípio da intervenção mínima, tendo esta o pressuposto de que, se com menos resolvo, não devo aplicar mais ou fazer mais forte.

A definição das soluções é uma actividade típica dos "conservation scientists", que deve ser suportada em estudos e análises dos problemas e dos efeitos das consequentes acções, e concretizada em estreito diálogo com os conservadoresrestauradores, os actores principais do vértice seguinte, das "acções".

No vértice das "acções" entendem-se todos os procedimentos necessários para concretizar as soluções e para as implementar em obra, respeitando as especificações e orientações provenientes do vértice antes discutido, aportando os conhecimentos e experiência específicos de quem as vai aplicar. Se na definição de uma dada solução se pressupõe uma forma implícita ou explícita de a concretizar, apenas os operacionais estão em situação de definir os limites de aplicabilidade, as capacidades do seu equipamento, a forma concreta de implementar a solução, etc.. Esta transposição das "soluções" para as "acções" acaba por ser uma fase crítica do processo que só o diálogo aberto e honesto permite resolver de forma adequada. Aç̧ões inexequíveis ou de resultado problemático podem decorrer mesmo de estudos feitos de forma honesta, e erros na fase de implementação podem acontecer mesmo em intervenções executadas por pessoal com preparação adequada, sem que necessariamente signifiquem negligência ou dolo. Em intervenções realizadas com profissionais devidamente preparados e com apoio de "conservation scientists", tais ocorrências podem ser evitadas ou fortemente minimizadas, sendo a lisura de processos e o seguimento de práticas validadas por princípios e pelos pares a garantia de que os "erros" serão ressalvados.

\section{A FASE DE IMPLEMENTAÇÃO. OS INTERESSADOS E OS INTERESSES}

À discussão do capítulo anterior devemos agora juntar os agentes centrais de todo o processo: o dono-de-obra e a autoridade de tutela. Em monumentos classificados, estes agentes agem e respondem em nome da Sociedade e adquirem, por isso, um estatuto especial em todo o processo que conduz a qualquer intervenção de conservação. Para simplificar, nesta análise englobaremos os dois agentes sob a designação genérica de "tutela".

À tutela cabe a responsabilidade primeira de identificar os valores que a Sociedade outorga ao monumento e de zelar para que esses valores sejam respeitados e mantidos. Cabe-lhe também a responsabilidade da gestão dos recursos postos ao serviço do monumento, numa esfera de acção que, naturalmente, vai muito para além das intervenções de conservação, as únicas que importa aqui considerar.

À tutela cabe, essencialmente, decidir. Decidir quando deve ser desencadeada a preparação de uma intervenção, quem deve associar a si para ajudar na preparação da intervenção, decidir o que vai ser implementado. Mas cabe-lhe também decidir as regras que vão reger a intervenção, escolher os agentes que a vão implementar e supervisionar todas as etapas dessa intervenção. Estas decisões não podem ser tidas como meros actos administrativos, pois elas podem configurar graus de risco muito significativos. Avançar para uma intervenção sem a devida preparação, atribuir uma empreitada pelo preço mais baixo, ou a agentes impreparados podem causar tantos ou mais danos que os erros de análise, as acções menos justificadas e as soluções inadequadas, com a agravante de que estes tendem a ser multiplicados quando as decisões são erradas.

As actividades de conservação e restauro compartilham com a indústria da construção múltiplos pontos em comum. Lidam com construções, usam produtos semelhantes e operam em estaleiros da mesma natureza e com regras semelhantes. Mas os objectos de actuação não são iguais e as acções processam-se sob contexto cultural que exige preparação específica e própria para actuar em ambiente desta índole.

Em muitos países, entre eles Portugal, a legislação não resolve eficazmente esta sobreposição de actividades, os conflitos de interesses são frequentes e nem sempre é fácil evitar que um empreiteiro mal preparado ganhe uma empreitada num monumento de grande responsabilidade. Noutras situações, é a política (traduzida em legislação inadequada) que impõe a prevalência dos preços mais baixos, nem sempre sinal de melhor aproveitamento de recursos e que, frequentemente, se conclui com trabalhos a mais ou realizações a menos.

A própria essência das intervenções de conservação impede que elas possam ser geridas sob uma lógica da indústria da construção. 0 conceito de projecto, exigido pela legislação aplicável, não pode seguir a mesma lógica. As acções não podem ser "desenhadas" de forma inequívoca, os materiais terão de respeitar as pré-existências, com as suas heterogeneidade e imprevisibilidade, as quantidades não podem ser antecipadas com grande rigor e as ocorrências imprevistas não são raras, nem são sempre evitáveis. Um projecto, no sentido que se dá habitualmente aos projectos de arquitectura e de engenharia não é um modelo aplicável às intervenções de conservação e, como 
tal, não deve servir de base, nem de jure nem de facto, à preparação, lançamento de concurso ou implementação das intervenções de conservação.

Em artigo recente (DELGADO RODRIGUES, 2015) lançámos a proposta de usar, na preparação de intervenções de conservação, unidades espaciais onde os problemas e as acções de conservação podem ser considerados relativamente homogéneos. Estas unidades permitem discretizar o objecto em tantas unidades quantas as necessárias para cobrir toda a área a intervencionar. Cada unidade é seguidamente descrita e caracterizada, em termos dos problemas e sua intensidade, e para cada uma são indicadas as acções previstas realizar.

A Figura 2 apresenta um exemplo onde tal divisão de unidades foi aplicada. Esta forma de representação é posteriormente usada pelo empreiteiro para reportar as acções implementadas e todas as ocorrências dignas de registro. Esta abordagem é mais consentânea com a metodologia de operação em obra, pois o conservadorrestaurador não planeia as suas acções por tipo de problema ou de acção, mas sim preferencialmente por sectores onde as acções, na sua maioria, são realizadas em simultâneo ou em sequência e não seguindo a lógica estrita de tratar cada anomalia de sua vez, como se poderia deduzir da forma habitual de indicar as necessidades de acção e suas quantidades respectivas. Sendo as dimensões das unidades calculadas com rigor (dentro dos limites que os suportes gráficos admitem) evitam-se ou minimizam-se fortemente as discrepâncias entre quantidades de trabalho previstas e realmente existentes, tornando as relações contratuais mais justas e com menor potencial de conflitualidade.

\section{CONCLUSÕES}

Nas intervenções de conservação do património cultural contam os resultados, mas conta também o processo. "Não me mostres os resultados, conta-me como lá chegaste" costumo dizer para sintetizar quão relevante é seguir metodologias seguras e suportadas em princípios.

Uma intervenção deve ser entendida como um encadeamento de diferentes fases, cada uma com conteúdos próprios e com actores preferenciais. As necessidades muito diferenciadas pressupõem que se convoquem competências diversas e que o processo se desenrole em ambiente de diálogo e com objectivo primeiro de preservar os valores que são reconhecidos no bem cultural.
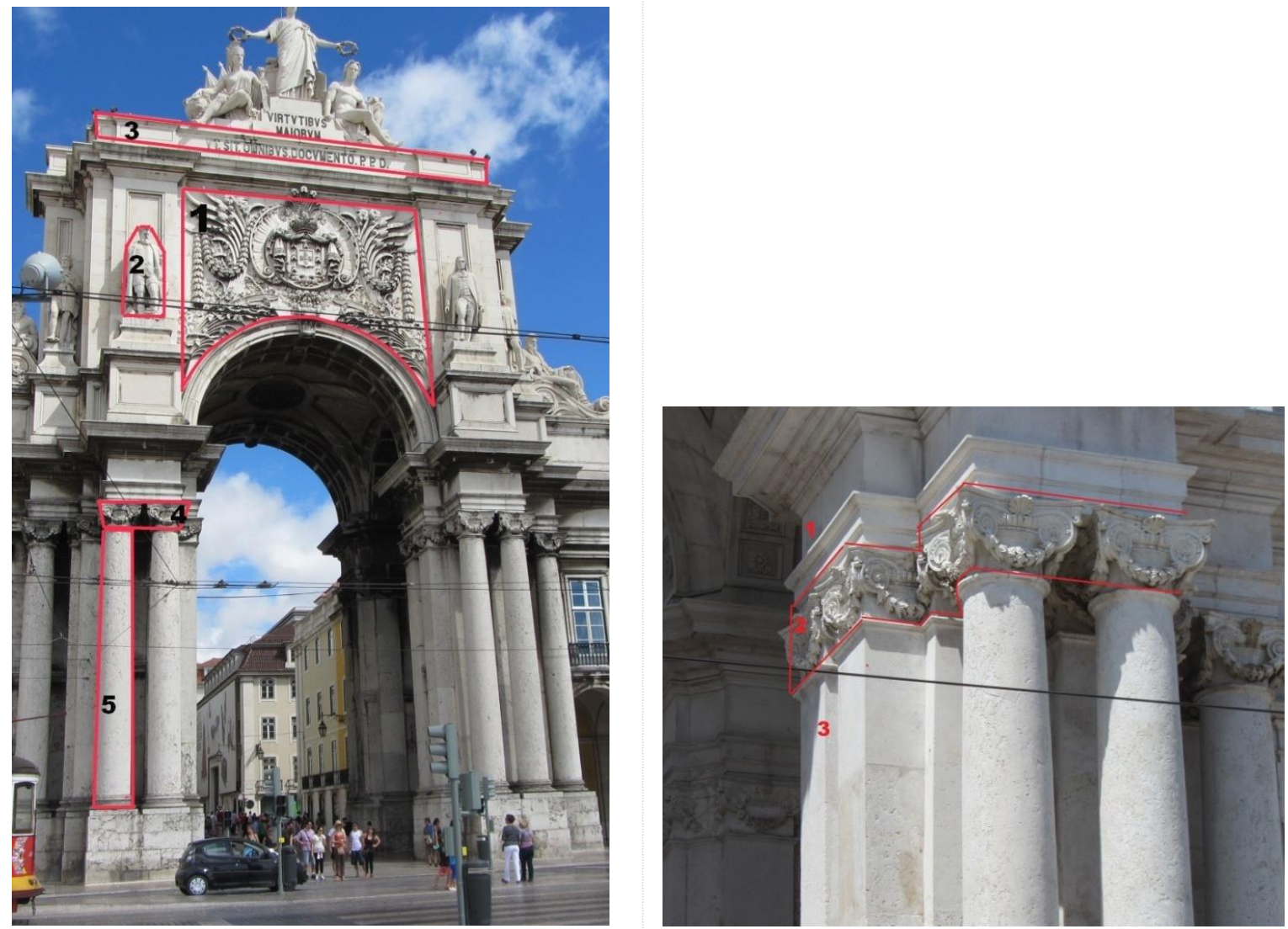

Figura 2. Arco da Rua Augusta, Lisboa. Visualização de unidades de intervenção caracterizadas por certa homogeneidade em termos da sua morfologia, problemas de deterioração e necessidades de conservação. A intervenção total era composta de 51 destas unidades. Adaptado de Delgado Rodrigues (2015) 
Se as questões ligadas à materialidade são o objecto directo da intervenção de conservação, não podemos esquecer que ela pressupõe, também, um conjunto de atitudes, pressupostos, decisões, opções e constrangimentos, facetas imateriais da intervenção que juntamos à "problemática do valor" como contributo da nossa própria actividade.

Se uma intervenção pressupõe a existência de problemas, estes implicam a procura de soluções e estas necessitam de ser concretizadas em acções. Quando correctamente interpretado, o triângulo "problemas-soluções-acções" representa a concretização material de uma intervenção e os seus vértices têm conteúdos razoavelmente consensuais. Mas importa também que as "arestas", representando aqui o diálogo ou a necessidade dele, sejam igualmente tidas em conta.

Os actores directos ou preferenciais de cada fase podem variar em número e especialização, mas sobre eles paira sempre um actor implícito, sempre presente, mas nem sempre actuante, a "tutela". Cabe a esta interpretar o sentir da Sociedade, decidir quando e porquê intervir, optar entre seguir processos completos ou encurtar etapas, optar pela qualidade ou pelo preço mais baixo, enfim, decidir em que grau as suas opções pretendem "respeitar" o bem cultural.

\section{AGRADECIMENTOS}

O autor agradece a Maria João Revez a leitura crítica do manuscrito.

\section{REFERÊNCIAS BIBLIOGRÁFICAS}

BRANDI, C. - Teoria do Restauro, Edições Orion, Amadora, 2006 (ed. original: Teoria del Restauro. Edizioni di Storia e Letteratura, Roma (1963))

DELGADO RODRIGUES, J. \& GROSSI, A. - The Compatibility Approach (Deliverable No. 03): INCO: International Scientific
Cooperation Projects (1998-2002) Contract No ICA3-CT-200210021, (2004).

DELGADO RODRIGUES, J. \& GROSSI, A. - Indicators and ratings for the compatibility assessment of conservation actions. Journal of Cultural Heritage, 8, 32-43. doi:101016/j.culher.2006.04.007, (2007).

DELGADO RODRIGUES, J. - Defining, mapping and assessing deterioration patterns in stone conservation projects. Journal of Cultural Heritage, 16(3), 267-275. doi:10.1016/j.culher.2014.06.007, (2015).

GAURI, K. L., GWINN, J. A., \& POPLI, R. K. - Performance criteria for stone treatment. Second International Symposium on the Deterioration of Building Stones, Athens, pp. 143-152, Technical University of Athens, (1976).

LAURENZI TABASSO, M. \& SIMON, S. - Testing methods and criteria for the selection/evaluation of products for the conservation of porous building materials. Reviews in Conservation, 7, 67-82, (2006).

MENESES, U. T. B. d. - O campo do Patrimônio Cultural: uma revisão de premissas. Comunicação apresentada ao Fórum Nacional do Patrimônio Cultural: Sistema Nacional de Patrimônio Cultural: desafios, estratégias e experiências para uma nova gestão, pp. 25-39. Ouro Preto/MG: IPHAN, (2009).

REVEZ, M. J. \& DELGADO RODRIGUES, J. Incompatibility risk assessment procedure for the cleaning of built heritage. Journal of Cultural Heritage, 18, 219-228. doi:10.1016/j.culher.2015.09.003, (2016).

SASSE, H. R. \& SNETHLAGE, R. - Methods for evaluation of stone conservation treatments. In N. S. Baer \& R. Snethlage (Eds.), Saving our Architectural Heritage: the Conservation of Historic Stone Structures (Dahlem Workshop Report), pp. 223-243. Chichester: John Wiley \& Sons Ltd. (1997).

Contribuição ao

1‥ Simpósio Brasileiro de Caracterização e Conservação da Pedra 14 a 16 de dezembro de 2016, Congonhas - MG

É de responsabilidade da comissão editorial do Simpósio a revisão gramatical, ortográfica, de citações e referências bibliográficas. As normas de submissão podem se diferenciar das desta revista. 